\title{
Conformational Tuning of Amylin by Charged SMA Copolymers
}

\author{
Bikash R. Sahoo, ${ }^{\left[{ }^{[a]}\right.}$ Christopher L. Souders II, ${ }^{[b]}$ Magdalena Ivanova, ${ }^{\left[{ }^{[a]}\right.}$ Zhou Deng, ${ }^{[a]}$ Takahiro W. Nakayama, ${ }^{[\mathrm{c}]}$ \\ Saba Suladze, ${ }^{[d]}$ Bernd Reif, ${ }^{[d]}$ Toshio Ando, ${ }^{[c]}$ Christopher J. Martyniuk, ${ }^{[b]}$ Ayyalusamy Ramamoorthyy ${ }^{*[a]}$
}

Email: ramamoor@umich.edu

\begin{abstract}
Human amylin is linked to type-2 diabetes and forms structurally heterogeneous amyloids that are pathologically relevant. Therefore, understanding the fundamental forces governing the formation of heterogeneous aggregates is important. Here, using derivatives (SMAQA $\left.{ }^{+} / \mathrm{SMAEA}^{-}\right)$of styrene-maleic-acid (SMA) copolymer $(\sim 2.2 \mathrm{kDa})$, we demonstrate the quick formation $(\sim$ in minutes) of amylin globulomers and fibers. High-speed AFM tracked the quick formation of de novo globular amylin oligomers and arrestment of fibrillation by SMAQA, whereas SMAEA accelerates amylin fibrillation. This observation is further supported by DOSY and STD NMR experiments. CD results show that SMAQA or SMAEA binding generates $\alpha$-helix or $\beta$-sheet rich amylin structures, respectively. Atomistic insights are revealed by $2 \mathrm{D}$ NMR and microseconds all-atom MD simulation. Together, this study highlights the importance of charge-charge interaction in tuning the fibrillation pathways of amylin that could be of therapeutic interest.
\end{abstract}

Protein aggregation is associated with both neurological and non-neurological disorders. Type-2 diabetes (T2D) is a nonneuropathic disease and a major health challenge, and at present $\sim 374$ million people are at an increased risk of T2D. Human islet-amyloid polypeptide (IAPP, or amylin) comprising of 37 residues is a histopathological hallmark of T2D. ${ }^{[1]}$ Amylin is co-synthesized and co-secreted with insulin at a defined stoichiometry ratio from pancreatic $\beta$-cells and primarily functions in glycemic control. ${ }^{[2]}$ The disordered soluble amylin aggregates form insoluble ordered $\beta$-sheet amyloids via intermediate heterogeneous and transient oligomer species that cause $\beta$-cell dysfunction..$^{[3]}$ Although, the molecular basis of the mechanism of amylin's amyloid formation and progression of T2D remain elusive, recent evidences show the generation of toxic oligomeric amylin species severe the pathological conditions via impairment of islet $\beta$-cell function and loss of $\beta$ cell mass. ${ }^{[1,4-7]}$ Modulation of the amyloid aggregation pathway to produce non-fibrillary and non-toxic species through specific or non-specific small-molecule interaction is a key strategy to control the disease progression. ${ }^{[8]}$ To this end, small molecules, peptides, antibodies, biopolymers, etc. have been designed to inhibit peptide aggregation by restraining the conformational state of the water-soluble monomer. ${ }^{[9-12]}$ Nevertheless, recently, reduction of the mass of cytotoxic oligomer species through rapid induction of non-crystalline fibers was achieved using small molecules, nanoparticles, polymers etc. ${ }^{[13-15]}$ To achieve this goal, several studies have exploited the strategy of designing specific inhibitors against the cationic but unstructured human amylin. Silver and iron nanoparticles were designed to sequester amylin monomers from fibers through electrostatic interactions. ${ }^{[16]}$ Both cationic and anionic polymers have been developed to either inhibit or accelerate amyloid

[a] Dr. B.R. Sahoo, Prof. Dr. A. Ramamoorthy: Biophysics and Department of Chemistry, University of Michigan, Ann Arbor, MI 48109 (USA)

[c] Mr. Souders CL II, Dr. Martyniuk CJ: College of Veterinary Medicine University of Florida, Gainesville, FL 32611 (USA)

[b] Dr. T.W. Nakayama, Prof. Dr. T. Ando: Bio-AFM Frontier Research Center, Kanazawa University, Kanazawa 9201192 (Japan)

[c] Prof. Dr. B. Reif, Dr. S. Suladze: Department of Chemistry, Technische Universität München, Garching 85748 (Germany)

[*] E-mail: ramamoor@umich.edu

Supporting information for this article is given via a link at the end of the document aggregation. ${ }^{[9,12]}$ Manipulation of surface charge on quantum dots, gold or polymeric nanoparticles has shown the potential in controlling amyloid aggregation. ${ }^{[17-20]}$ Further, strong electrostatic interaction of amylin with anionic lipid membrane has been shown to modulate the phenotype of the amylin species. ${ }^{[21,22]}$ Nevertheless, the role of hydrophobic and electrostatic energetics in driving amyloid fibrillation and polymorphism are still poorly understood. Thus, a detailed understanding of the role of hydrophobic and electrostatic interactions in fine-tuning amylin's conformation is important to better understand the pathology of T2D progression.

Here, we use two different polymers to study amylin aggregation that were designed with a variable functionalization specifying its polarity as shown in Figure S1. The cationic SMAQA(+) and anionic SMAEA(-) polymers share an invariable styrene hydrophobic aromatic moiety known to bind amyloids (Figure S1). ${ }^{[23-25]}$ Both polymers show polydispersity after synthesis with a molecular size of $\sim 2.2 \mathrm{kDa}$. The activity of SMAQA and SMAEA on amylin is accessed using thioflavin-T (ThT) fluorescence. Real-time monitoring of the aggregation kinetic of $5 \mu \mathrm{M}$ amylin dissolved in sodium acetate ( $\mathrm{NaAc}$ ), $\mathrm{pH} 5.5$, using ThT assay showed SMAQA and SMAEA delay and accelerate amylin aggregation, respectively (see details in Supporting Results; Figure S2). It should be noted that, although SMAEA (not SMAQA) polymer interference with $\mathrm{ThT},{ }^{[26]}$ the binding of ThT to amyloid fibers is selective and yield relatively strong fluorescence (Figures S3 and S4). Next, we monitored the aggregation of amylin on real-time using high-speed atomic force microscopy (HS-AFM). The reaction was carried out in the presence of 5 mole \% sonicated amylin fiber seeds (prepared from $5 \mu \mathrm{M}$ monomers) for two main reasons: (i) to monitor the relative binding affinity of amylin monomers to polymers vs seeds, and (ii) to proceed the fibrillation of amylin within a timescale of HS-AFM observation. ${ }^{[12]}$ First, we monitored the aggregation reaction in the presence of amylin fiber seeds on the HS-AFM stage by titrating with $5 \mu \mathrm{M}$ of freshly dissolved amylin monomers. As shown in Figure S5, growth of amylin fibers and de novo formation of fibers were observed after the addition of monomers (Video SV1). Next, we conducted this reaction in the presence of SMAQA or SMAEA $(11 \mu \mathrm{g} / \mathrm{mL})$ on the mica surface. Interestingly, HS-AFM revealed the formation of de novo globular amylin species when monomers were allowed to mix with the SMAQA+seed sample (Figure 1a-c, Video SV2). At a time-point of $225 \mathrm{~s}$, a de novo globular amylin species of size $\approx 18 \mathrm{~nm}$ was isolated (Figure 1a, red box). The size and growth of the globumer was next scanned for several hundreds of seconds within a scale of 150 pixels $(1$ pixel $=2 \mathrm{~nm})$ by monitoring the grey components in ImageJ (Figure 1b). As shown in Figure 1 ( $b$ and d), the time-lapse HS-AFM observation revealed the formation of three distinct de novo globulomers within the selected region $(300 \mathrm{~nm})$. The de novo globumer formation and the increase in the size is illustrated in Video SV3. Nevertheless, at a time-point of $1335 \mathrm{~s}$, several globulomers of size $>10 \mathrm{~nm}$ were identified that do not proceed to fibrillation (Video SV2). On the contrary, amylin monomers showed fibrillation in the presence of SMAEA (Figure. 1e, denoted with red arrows); the growth of fibers was observed at a time-point of 225 s. A bidirectional growth of amylin fibers observed in the presence of SMAEA is similar to that observed in the absence of polymers (Figure 1f, Video SV4 and SV5). Kymographs of fibrillation of the selected fiber (Figure 1e, red arrow) in the presence of SMAEA showed a growth of $\approx 40$ to $50 \mathrm{~nm}$ in both 
(a)

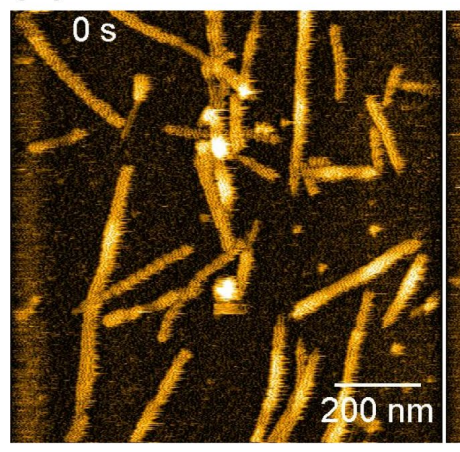

(b)

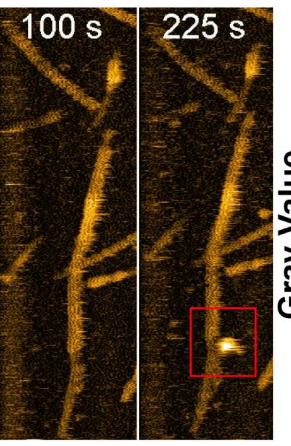

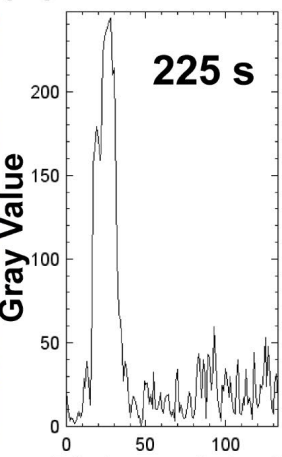

Distance (pixels) (c)

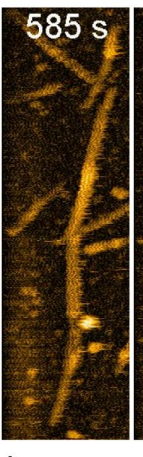

(d)

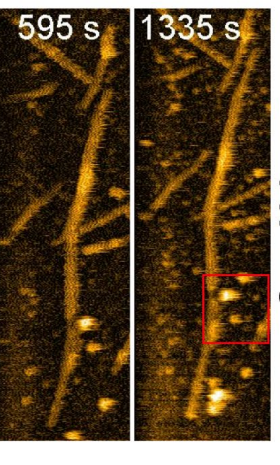

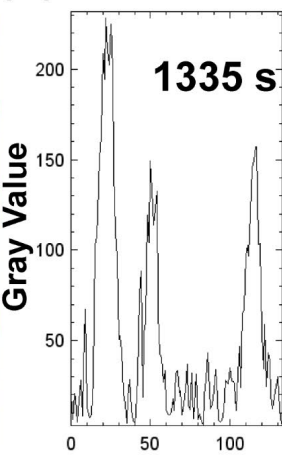

Distance (pixels (e)

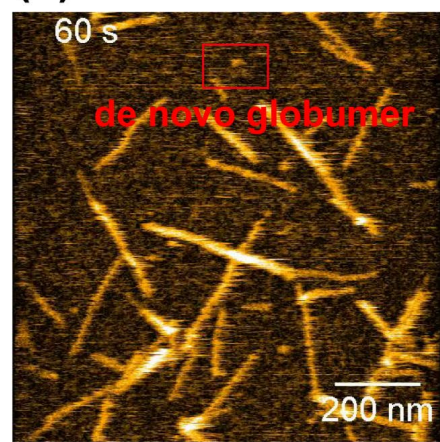

(f)

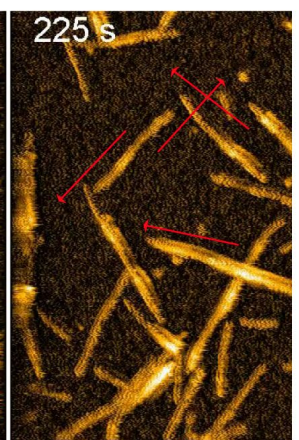

(g)

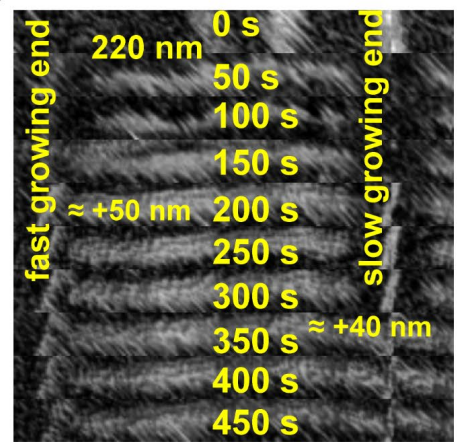

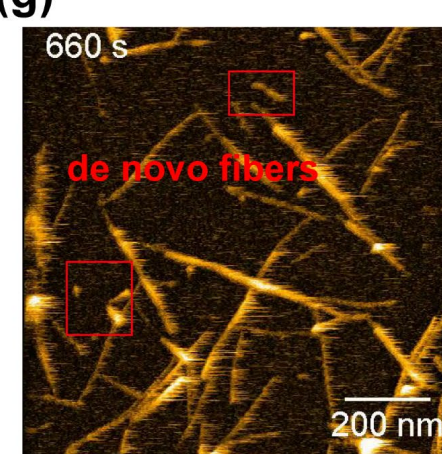

Figure 1. Real-time monitoring of the effect of SMA copolymers on amylin conformation and aggregation. HS-AFM observation of 5 $\mu \mathrm{M}$ amylin dissolved in $30 \mathrm{mM}$ NaAC, $\mathrm{pH} 5.5$ in the presence of $5.5 \mu \mathrm{g} / \mathrm{mL}$ SMAQA (a-d) and SMAEA (e-g). The de novo globulomer formation in amylin in the presence of SMAQA is shown inside a red box ( $a$ and $c)$. The size of the globulomers ( $b$ and $d)$ were calculated using Image $J$ where 1 pixel= $2 \mathrm{~nm}$. The bidirectional fibril growth in amylin in the presence of SMAEA is shown by arrows (e) and the fast and slow growing ends are quantified using ImageJ (f). The de novo amylin fiber formation and growth in the presence of SMAEA are shown inside a box (g). The amylin fibrillation in the absence of SMA copolymers are shown in Figure S3.

direction within a time-interval of 200s (Figure 1f, Video SV4). Nevertheless, unlike in the presence of SMAQA, HS-AFM revealed the formation of de novo amylin globulomers that grow to form fibers in the presence of SMAEA (Figure 1 (e and g)), Video SV6). Amylin monomers $(5 \mu \mathrm{M})$ titrated with SMAQA or SMAEA (11 $\mu \mathrm{g} / \mathrm{mL}$ ) showed generation of ThT negative (no fiber; low ThT intensity) or positive (fiber; high ThT intensity) species, respectively (Figures $2 a$ and S6).

Conformational analysis showed both polymers to be inducing distinct secondary structural changes in amylin. Titration of $25 \mu \mathrm{M}$ amylin with 11 or $27.5 \mu \mathrm{g} / \mathrm{mL}$ of SMAQA showed no significant structural change in contrast to SMAEA (Figure S7a,b). Increasing SMAQA concentration to $55 \mu \mathrm{g} / \mathrm{mL}$ generated a mixed conformational state in amylin characterized by a helical conformation with CD minima centered at $\approx 208$ and $222 \mathrm{~nm}$ (Figure 2a). On the contrary, 11 or $27.5 \mu \mathrm{g} / \mathrm{mL}$ of SMAEA presented a shift in CD minimum from $\approx 200 \mathrm{~nm}$ to $\approx 227 \mathrm{~nm}$ (Figure S7b), and a further decrease and increase in molar ellipticity $[\Theta]$ at $\approx 200 \mathrm{~nm}$ and $\approx 227 \mathrm{~nm}$, respectively, when SMAEA concentration was increased to $55 \mu \mathrm{g} / \mathrm{mL}$ (Figure 2a). It should be noted that the copolymer concentration used were below their tested critical micellar concentration (Figure S8), and the peptide:polymer stoichiometry was kept unchanged. Deconvolution of secondary structures by BeStSel program ${ }^{[27]}$ from the time-lapse CD measurements yielded an initial $\sim 18.3 \%$ $\alpha$-helix, $\sim 1.8 \%$ parallel $\beta$-sheet and $\sim 12.4 \%$ antiparallel $\beta$-sheet structures in $25 \mu \mathrm{M}$ amylin (Figure $2 \mathrm{~b}$ ) following an increase in $\beta$ sheet content on day- 2 and day-7 indicating amylin's aggregation. ${ }^{[12]}$ Amylin mixed with $55 \mu \mathrm{g} / \mathrm{mL}$ SMAEA (generated within few minutes of titration) presented $\sim 37 \%$ a-helix, $\sim 1.4 \%$ parallel $\beta$-sheet and $\sim 32.1 \%$ antiparallel $\beta$-sheet (Figure $2 b$ ). On the other hand, amylin mixed with $55 \mu \mathrm{g} / \mathrm{mL}$ SMAQA presented $36.3 \%$-helix and $13.4 \%$ antiparallel $\beta$-sheet. Such random-coil to helical structure transition has also been observed in amylin interacting with small molecule inhibitors containing quaternary ammonium group as well as in dodecylphosphocholine micelles. ${ }^{[28,29]}$ It should be noted that, free SMAEA and SMAQA does not show a characteristic CD spectrum (Figure S9); however, in the amylin bound state, the possibility of SMA polymer's interference with $C D$ absorption may not be ruled out. This is verified by measuring the amide-I absorption band using FT-IR spectroscopy that selectively determine the backbone conformation of amylin. FT-IR spectrum revealed $\beta$-sheet conformation for SMAEA-amylin complex $\left(\sim 1637 \mathrm{~cm}^{-1}\right.$, spectra resembles amylin fibers), whereas a partial folded helical conformation is identified for SMAQA-amylin complex $(\sim 1656$ $\mathrm{cm}^{-1}$, spectra resembles amylin monomers) (Figure S10). Together, the CD and FT-IR results indicate that the SMAQAamylin shorter assemblies identified as globular in HS-AFM are helical. Such spherical amylin species characterized by $\alpha$-helix conformation has been previously reported. ${ }^{[30,31]}$ TEM analysis showed fibrillary morphology in amylin $(25 \mu \mathrm{M})$ mixed with $55 \mu \mathrm{g} / \mathrm{mL}$ SMAEA, and major spherical morphology in amylinSMAQA mixture (Figure S11). The rapid structural change induced by SMAEA even at a very low concentration (Figure $\mathrm{S} 7 \mathrm{~b})$ is expected to be due to charge-charge interactions (amylin: +3 at $\mathrm{pH}$ 5.5). A similar observation has been reported for $A \beta$ interacting with an oppositely charged polymer. ${ }^{[12]}$ The observation from amylin was further probed by altering the buffer $\mathrm{pH}$ from 5.5 to 8.5 where amylin's net charge is $\approx 0$ and showed an $\alpha$-helical structure in the presence of $55 \mu \mathrm{g} / \mathrm{mL}$ SMAEA (Figure S12), which resembles amylin's structure at pH 5.5 in the presence of SMAQA (Figure 2a). These results indicate that amylin's helical conformation in the presence of polymers is mainly induced by hydrophobic interactions.

The polymer-amylin interactions were next studied using NMR and molecular dynamics (MD) simulation. $2 \mathrm{D}{ }^{1} \mathrm{H} /{ }^{15} \mathrm{~N}$ SOFASTHMQC showed a dispersed correlation spectrum for $25 \mu \mathrm{M}$ amylin (Figure 2c, red) and resonances were assigned as reported elsewhere. ${ }^{[32]}$ Titration of $55 \mu \mathrm{g} / \mathrm{mL}$ SMAQA resulted in 
(a)
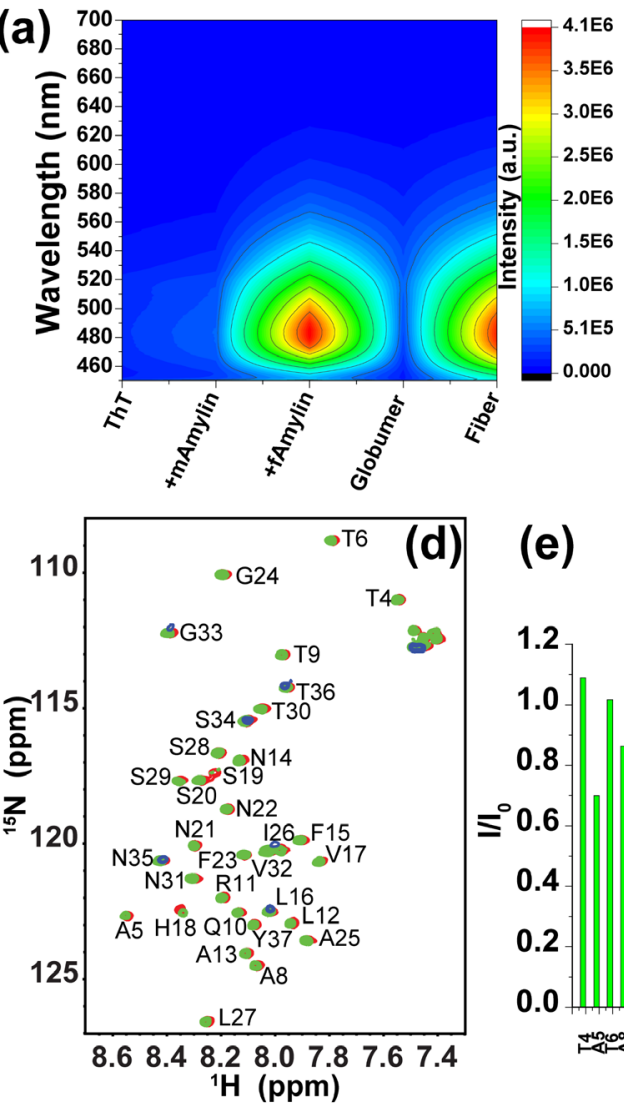

(b)

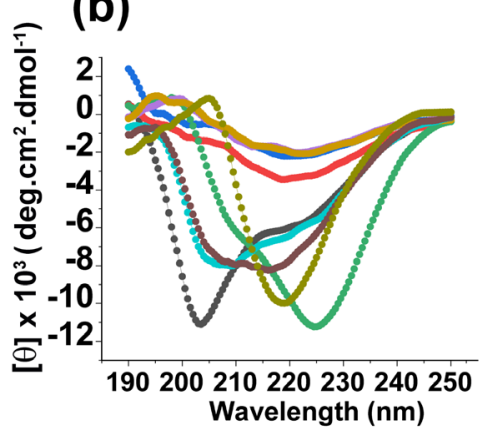

(e)

1.2

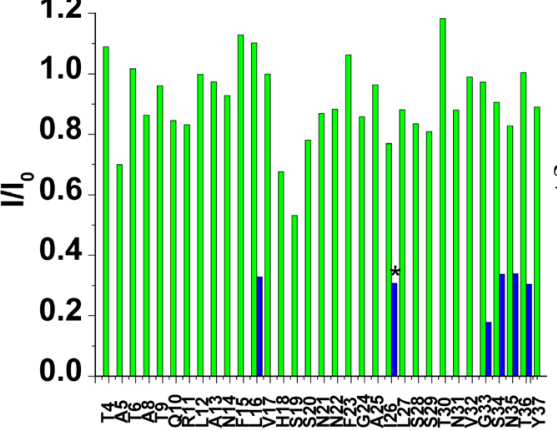

(f) (c)

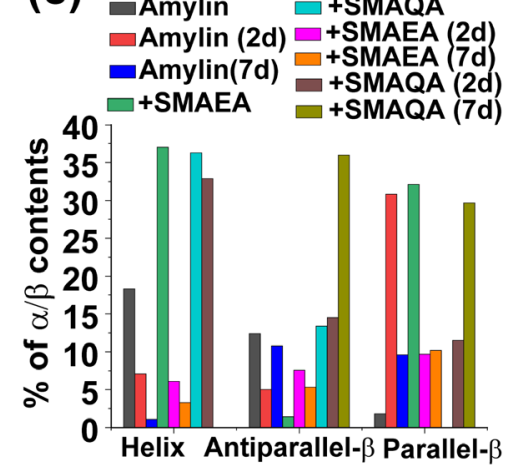

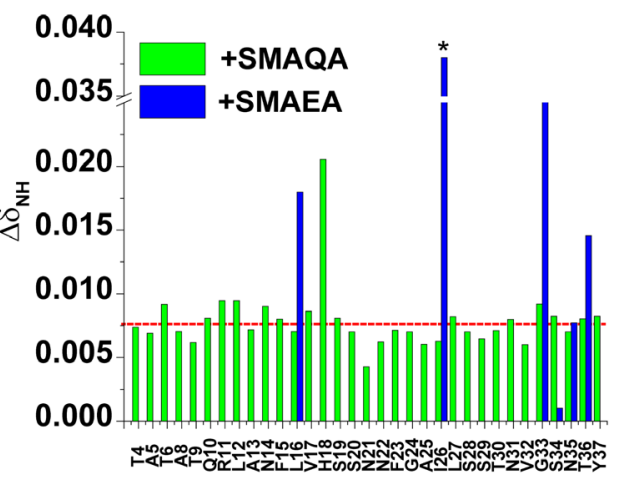

Figure 2. Effect of SMA copolymers on amylin conformation. (a) $2 \mathrm{D}$ plot showing the fluorescence of $10 \mu \mathrm{M}$ of ThT mixed without or with $5 \mu \mathrm{M}$ amylin monomer (mAmylin); preformed fiber (fAmylin); filtered SMAQA (11 $\mu \mathrm{g} / \mathrm{mL})+5 \mu \mathrm{M}$ amylin (globumer); or filtered SMAEA $(11 \mu \mathrm{g} / \mathrm{mL})+5 \mu \mathrm{M}$ amylin (Fiber) (see methods; also refer Figure Sx). (b) Time-lapse far-UV CD measurement of $25 \mu \mathrm{M}$ amylin dissolved in $30 \mathrm{mM} \mathrm{NaAc}, \mathrm{pH} 5.5$ in the presence and absence of $55 \mu \mathrm{g} / \mathrm{mL}$ SMA copolymers as indicated in colors ((c), top). (c) The \% of $\alpha / \beta$ contents were calculated from the respective $\mathrm{CD}$ spectra showing time-variable conformational changes using the BeStSel program. (d) $2 \mathrm{D}{ }^{15} \mathrm{~N} /{ }^{1} \mathrm{H}$ SOFAST-HMQC spectra of $25 \mu \mathrm{M}{ }^{15} \mathrm{~N}$-labeled amylin in the absence (red) and presence of $55 \mu \mathrm{g} / \mathrm{mL}$ SMAQA (green) or SMAEA (blue) recorded on a $800 \mathrm{MHz}$ NMR spectrometer at $25^{\circ} \mathrm{C}$. (e) Peak intensities measured from SOFAST-HMQC spectra: peak intensities of amylin residues in the absence $\left(\mathrm{I}_{0}\right)$ and in the presence of polymer (I); SMAEA (blue) or SMAQA (green). * indicates peak intensities from I26/V32 in the SMAEA-amlylin sample. (f) Chemical shift purturbations (CSPs) calculated using $\Delta \delta_{N H}=\sqrt{\left(\delta^{1} H\right)^{2}+0.154 \times\left(\delta^{15} N\right)^{2}}$. The dashed line represents the average $\left(\mathrm{CSP}_{\text {avg }}\right)$ value calculated for the amylin-SMAQA mixture (CSP avg amylin-SMAEA is not shown due to significant line broadening for most of the residues).

line-broadening (within the NMR measurement time, i.e. $\approx 1$ hour) for most of the observed resonances (Figure 2c, green) indicating the formation of large aggregates. In particular, residues $\mathrm{A} 5, \mathrm{H} 18, \mathrm{~S} 19$ and $\mathrm{S} 20$ showed $\approx>25 \%$ decrease in signal intensity. Strikingly, most of the resonances disappeared upon the addition of $55 \mu \mathrm{g} / \mathrm{mL}$ SMAEA, except L16, I26/V32 and residues spanning 33-36 that exhibited $>75 \%$ reduction in signal intensity (Figure 2d, blue). This indicates the formation of large aggregates or fibers which are usually undetectable by solution NMR. On the other hand, a comparatively small signal intensity reduction was observed in SMAQA-amylin sample (Figure 2d, green) indicating an early formation of oligomers; however, these aggregates are unlikely to be fibers that are usually undetectable. These results correlate with the HS-AFM observations that showed the formation of amylin globulomers and fibers upon binding to SMAQA and SMAEA, respectively (Figure $1 \mathrm{c}$ and $\mathrm{f}$ ). The chemical shift perturbation $\left(\Delta \bar{\delta}_{\mathrm{NH}}\right)$ analysis further identified several $\mathrm{N}$ - and $\mathrm{C}$-terminal residues with $\Delta \delta_{\mathrm{NH}}$ above the average value which could be due to SMAQA binding induced amylin oligomerization (Figure 2e). Notably, the six observed amylin residues presented a substantial $\Delta \bar{\delta}_{\mathrm{NH}}$ in the SMAEA-amylin mixture (Figure 2e).

${ }^{1} \mathrm{H}$ NMR spectra further ascertained amylin fibrillation in the presence of SMAEA with significant broadening of amide- $\mathrm{NH}$ resonances (spanning $\approx 7.5$ to $8.5 \mathrm{ppm}$ ) immediately after titrating $25 \mu \mathrm{M}$ amylin with $55 \mu \mathrm{g} / \mathrm{mL}$ SMAEA (Figure 3b, blue); note the NMR measurement time-scale of $<30$ minutes. On the other hand, SMAQA treated amylin presented a well-dispersed amide proton resonances (Figure 3a, blue). Visual inspection showed a turbid and precipitated SMAEA-amylin sample on day7 whereas the SMAQA-amylin sample was found to be transparent (Figure 3, top center). Titration of both SMA polymers rapidly induced amylin oligomers characterized by the peak near $\approx-0.5 \mathrm{ppm}$ (marked with ${ }^{*}$ ) in Figure $3(\mathrm{a}$ and $\mathrm{b}$ ). Remarkably, this oligomer peak disappears on day-7 only for the SMAEA-amylin sample indicating the fibril growth. In contrast, the oligomers in SMAQA sample mixture were stable indicating their non-seeding activity. Proton NMR spectrum of the SMAQA $(55 \mu \mathrm{g} / \mathrm{mL})$ mixed amylin $(25 \mu \mathrm{M})$ sample filtered using a $30 \mathrm{kDa}$ filter showed the absence of SMAQA and low-ordered NMR detectable aggregates (Figure. S13). This is further validated using saturation transfer difference (STD) NMR measurements as shown in Figure 3 (c and d). Saturation of amylin oligomer peak $(\approx-0.5 \mathrm{ppm}$, blue spectra) do not show a transfer of magnetization from amylin species to SMAEA polymer indicating dissociation of polymers upon amylin aggregation. Saturation of $-\mathrm{NR}_{3}{ }^{+}$protons (3.078 ppm, pink) in SMAQA showed a slight magnetization transfer to aromatic styrene protons $\approx 7 \mathrm{ppm}$ (Figure 3c, pink); however, no magnetization transfer to amylin was observed. Further, saturation of protons in the styreneamide overlap region $(\approx 7.2 \mathrm{ppm})$ showed no detectable magnetization transfer. DOSY NMR also identified the presence of free polymers (Figure S14) in polymer-amyin mixture whose diffusion rate $\left(\sim 1 \times 10^{-10} \mathrm{~m} / \mathrm{s}^{2}\right)$ is faster as compared to the polymer induced amylin aggregates $\left(\sim 2 \times 10^{-11} \mathrm{~m} / \mathrm{s}^{2}\right)$.

All-atom MD simulations presented a fast (at $\approx 0.6 \mathrm{~ns}$ for SMAEA) and slow (at $\approx 125$ ns for SMAQA) interaction between polymer and amylin (initially separated by $\geq 1 \mathrm{~nm}$ ). (Figure $\mathrm{S} 15$ ). 

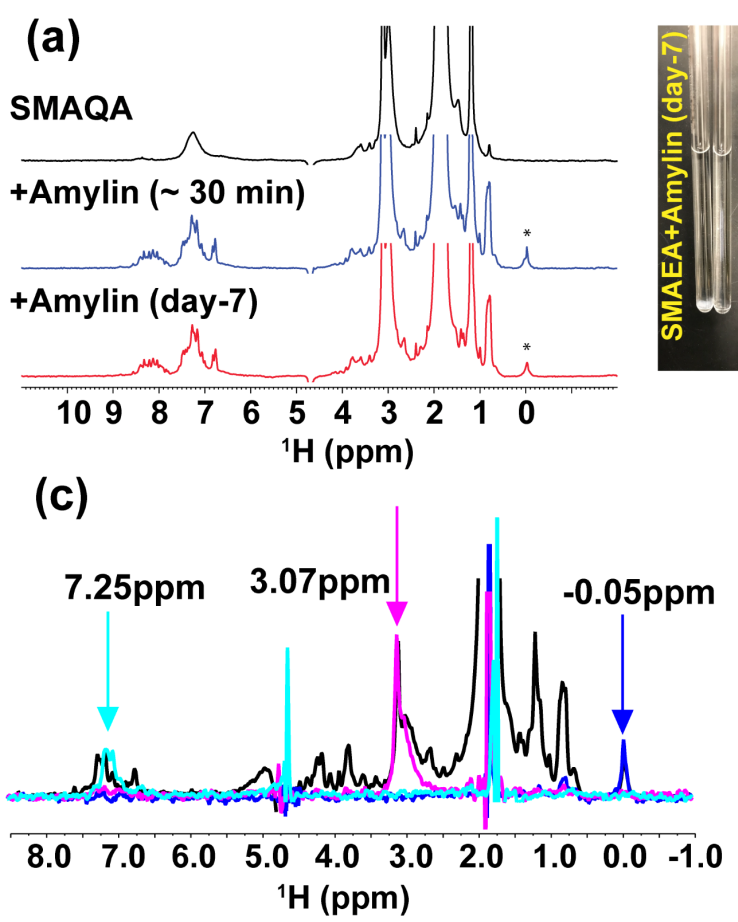

(e)
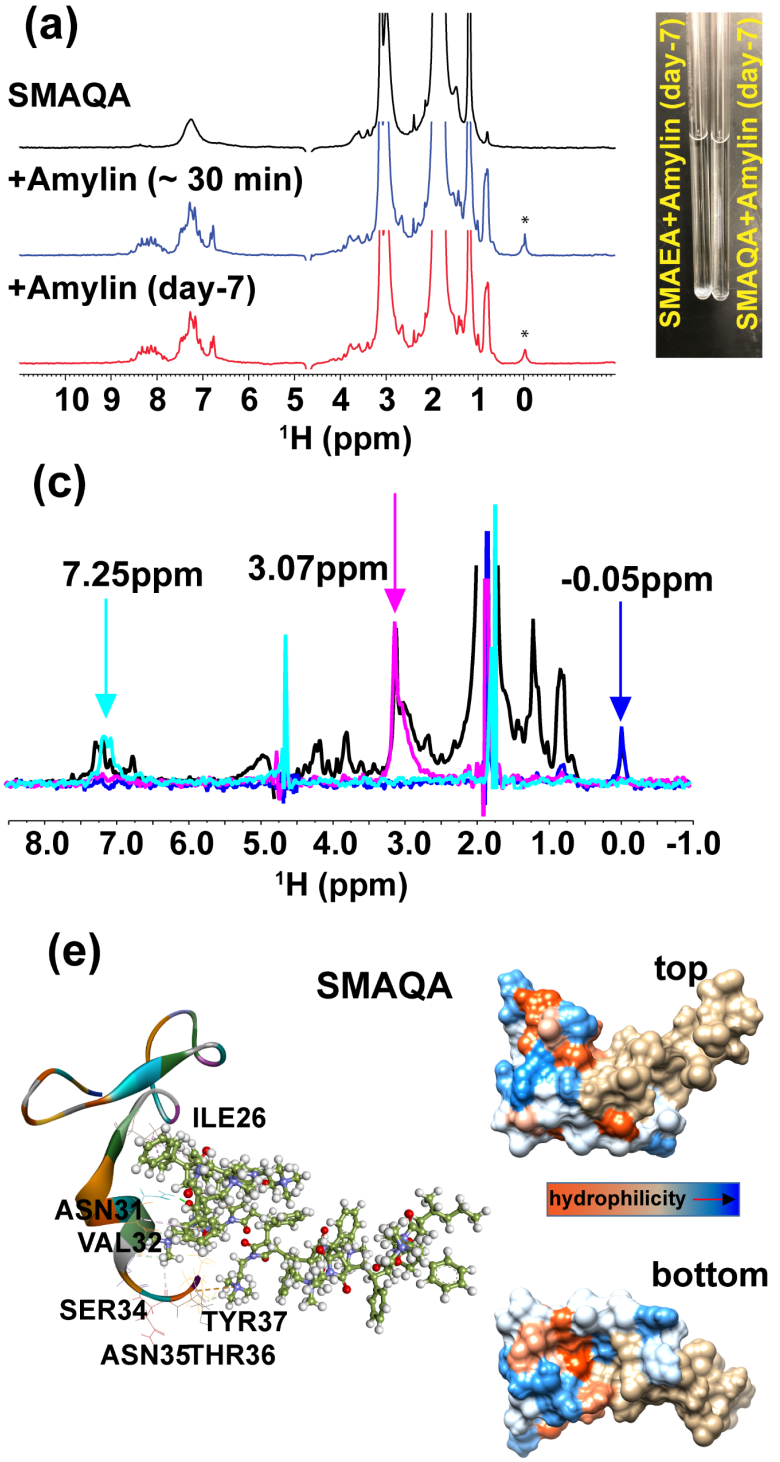
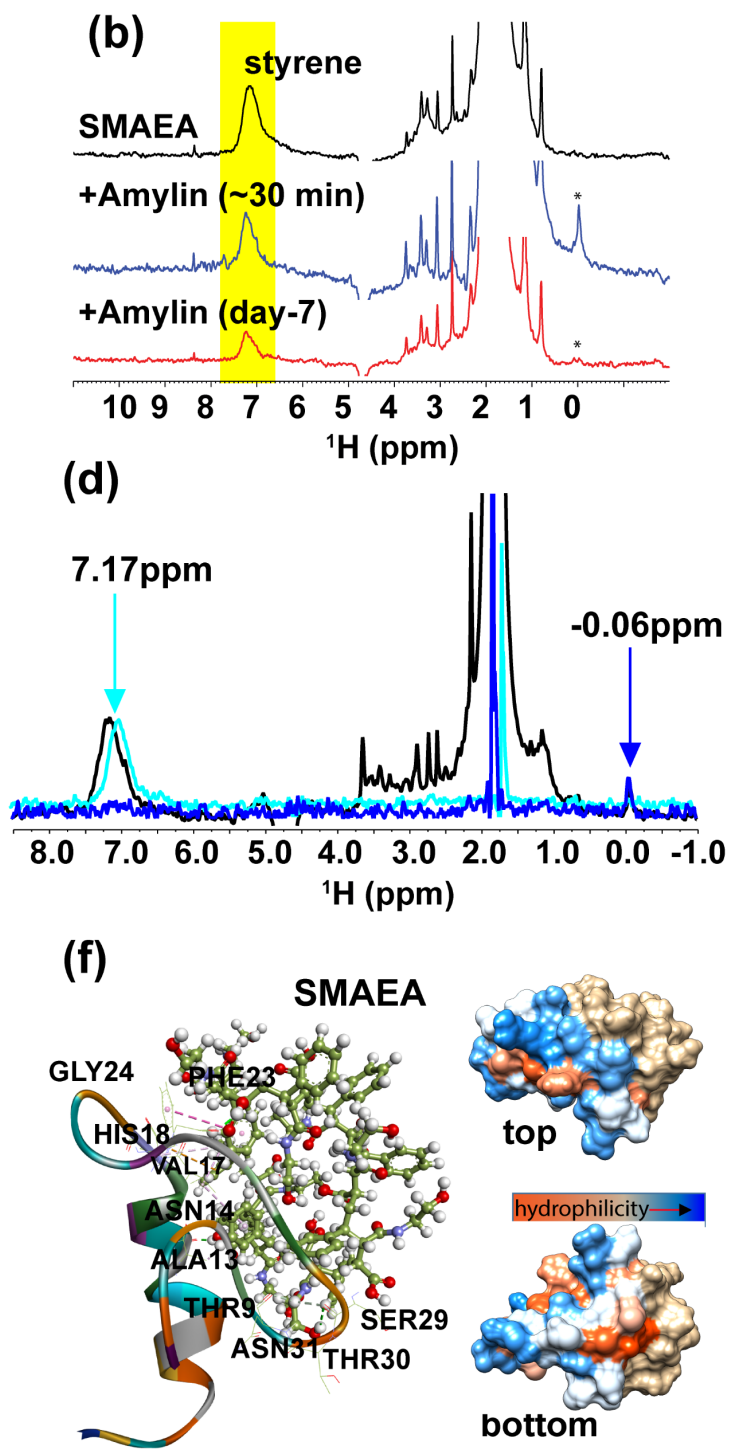

Figure 3. Structural interactions between amylin and SMA copolymers. (a-b) Time-lapse ${ }^{1} \mathrm{H}$ NMR spectra of $55 \mu \mathrm{g} / \mathrm{mL}$ SMAEA or SMAQA (black) mixed with $25 \mu \mathrm{M}$ amylin (blue and red) recorded on a $500 \mathrm{MHz}$ NMR spectrometer at $25^{\circ} \mathrm{C}$ at the indicated time. The styrene peak is highlighted in yellow. A broad low intensity peak from amylin oligomers appeared near $\approx-0.5 \mathrm{ppm}$ is indicated with *. The SMAEA-amylin solution showed precipitation whereas the SMAQA-amylin samples were clear at the end of day-7 as shown in the center (top). (c-d) STD NMR spectra of $25 \mu \mathrm{M}$ amylin in the presence of $55 \mu \mathrm{g} / \mathrm{mL}$ SMAQA (c) and SMAEA (d) recorded on a $500 \mathrm{MHz}$ NMR spectrometer at $25^{\circ} \mathrm{C}$. The reference spectrum is shown in black and the saturation transfer difference spectrum is shown in the indicted colors (blue or pink) referring to the signal that was saturated as shown by arrow. X-axis offset is used for the cyan spectrum to avoid spectral overlapping and visual clarity. Snapshots obtained at 500 ns MD simulations are shown for (e) SMAQA-amylin and (f) SMAEAamylin complexes. The interaction between polymer (ball-stick) with amylin (cartoon) were generated using DSV v17.2.0. The amylin binding residues that form hydrogen bonding, electrostatic, hydrophobic and $\pi-\pi$ interactions are labeled (shown as dashed lines). The top and bottom views of the hydrophobic surface maps of the complexes are shown on the right of the respective MD complex.

As compared to SMAQA, SMAEA presented higher intermolecular hydrogen bonds ( $\mathrm{H}$-bond) indicating tight binding (Figure S16). RMSD analysis presented a backbone dynamics for both amylin-polymer complex systems (Figure S17a). RMSF analysis calculated a comparatively high fluctuations (average $>4 \AA$ ) in SMAQA-amylin complex as compared to SMAEA-amylin (residue 7-16 showed minimum fluctuations) complex (average $\sim 2.7 \AA$ ) (Figure $\mathrm{S} 17 \mathrm{~b}$ ). A detailed analysis is provided in supporting results. A small secondary structure perturbation was observed in SMAEA-amylin as compared to SMAQA-amylin (Figure S18). Atomistic interaction analysis (structure derived at $500 \mathrm{~ns}$ ) showed SMAQA forms hydrophobic (Ile26, Val32 and Tyr37) and $\mathrm{H}$-bond interactions (Asn31, Ser34, Asn35 and Thr36) with amylin (Figure 3e, Table S1). SMAQA selectively binds to amylin's $C$-terminus residues following induction of $\beta$ sheets in the $\mathrm{N}$-terminus that resembles our previous observation for amyloid- $\beta$ interacting with a cationic polymer ${ }^{[12]}$
Binding of SMAQA with one of the two $\beta$-sheets (14-19 and 3136 ) that form fibers could be a possible mechanism of inhibition of amylin fibrillation and formation of globular oligomers with mixed $\alpha / \beta$ conformation (Figure 2a). ${ }^{[33]}$ Unlike SMAQA, SMAEA interacts with amylin (structure derived at $500 \mathrm{~ns}$ ) at both $\mathrm{N}$ - and C-terminus (Figure 3f, Table S1). Ala13 and Val17 showed hydrophobic packing and $\pi-\pi \mathrm{T}$-shape interaction was mediated by Phe23 (Figure 3f). The protonated His 18 forms $\mathrm{H}$-bond and electrostatic cation- $\pi$ bond with SMAEA. The $\mathrm{N}$-terminal residue Arg11 showed no interaction with SMAEA. However, transient $\mathrm{H}$-bond formation between SMAEA and Lys1 was identified during the first $\sim 350 \mathrm{~ns}$ (Figures S19, S20). The electrostatic interaction by SMAEA could neutralize the positive amylin charge facilitating its quick aggregation as observed experimentally.[34] It should be noted that structural map generated from MD simulations cannot be compared directly 
bioRxiv preprint doi: https://doi.org/10.1101/2020.04.23.057547; this version posted April 27, 2020. The copyright holder for this preprint (which was not certified by peer review) is the author/funder, who has granted bioRxiv a license to display the preprint in perpetuity. It is made available under aCC-BY-NC-ND 4.0 International license.

with the reported experimental results as per the time-scale of measurement is concerned. However, the interacting forces driving the complex formation in different SMA copolymers correlate well with the experimental observations

In conclusion, we have shown distinct effects of two different SMA copolymers on amylin aggregation. The cationic SMAQA drives the formation of amylin globulomers, whereas the anionic SMAEA accelerates amyloid formation. The reported biophysical results indicate that charge-charge interactions to suppress the formation of amylin intermediates by quickly directing them to form $\beta$-sheet containing fibers as demonstrated using SMAEA. On the other hand, hydrophobic interaction as observed with SMAQA favors stabilization of globular amylin intermediates. Reported mechanistic results reveal SMAQA targets amylin's C-terminus that constraints the overall peptide plasticity to form metastable water insoluble fibers. It is remarkable that this finding reflects the cationic amylin's higher tendency to interact with anionic biomolecules such as anionic lipids resulting in the rapid formation of amyloids. The role of intermolecular charge-charge interactions is further confirmed by the experimental observation of cationic amphiphilic biomolecules (like that of SMAQA) restricting amylin's fibrillation. Thus, this study delineates the effects of SMA copolymers that are capable of solubilizing lipids and penetrating the cell membrane. ${ }^{[35-39]}$ The charge and hydrophobic interaction mediated generation of morphologically distinct amylin species reported here could be useful in designing strategic amyloid inhibitors. In vitro and in vivo results showed SMAEA and SMAQA polymers were not toxic to kidney HEK293T cells and zebrafish embryo (Figure S21). Further, the amylin species generated by SMAEA/SMAQA were also found not cytotoxic in vitro (Figure S22). Further studies to explore the therapeutic efficacy of these targeted polymers would pave avenues for potential clinical applications.

\section{Acknowledgements}

This study was supported by NIH (AG048934 to A.R.), and the computations by Osaka University (ICR-18-02).

Keywords: Amylin •IAPP • Type-II diabetes $•$ Amyloid $・$ SMA

\section{References}

[1] R. Langen, T. Gurlo, A. V Matveyenko, P. C. Butler, 2013 62, 327-335.

[2] H. C. Fehmann, V. Weber, R. Göke, B. Göke, R. Arnold, FEBS Lett. 1990, 262, 279-281.

[3] P. Cao, P. Marek, H. Noor, V. Patsalo, L. H. Tu, H. Wang, A. Abedini, D. P. Raleigh, FEBS Lett. 2013, 587, 11061118.

[4] T. Gurlo, S. Ryazantsev, C. J. Huang, M. W. Yeh, H. A. Reber, O. J. Hines, T. D. O'Brien, C. G. Glabe, P. C. Butler, Am. J. Pathol. 2010, 176, 861-869.

[5] C. Y. Lin, T. Gurlo, R. Kayed, A. E. Butler, L. Haataja, C G. Glabe, P. C. Butler, Diabetes 2007, 56, 1324-1332.

[6] J. F. Rivera, T. Gurlo, M. Daval, C. J. Huang, A. V. Matveyenko, P. C. Butler, S. Costes, Cell Death Differ. 2011, 18, 415-426.

[7] R. A. Ritzel, J. J. Meier, C. Y. Lin, J. D. Veldhuis, P. C. Butler, Diabetes 2007, 56, 65-71.

[8] L. M. Young, L.-H. Tu, D. P. Raleigh, A. E. Ashcroft, S. E. Radford, n.d., DOI 10.1039/c7sc00620a.

[9] E. H. Pilkington, M. Lai, X. Ge, W. J. Stanley, B. Wang, M. Wang, A. Kakinen, M. A. Sani, M. R. Whittaker, E. N. Gurzov, et al., Biomacromolecules 2017, 18, 4249-4260.

[10] A. Nath, D. E. Schlamadinger, E. Rhoades, A. D. Miranker, Biochemistry 2015, 54, 3555-3564.

[11] B. R. Sahoo, T. Genjo, S. J. Cox, A. K. Stoddard, G. M. Anantharamaiah, C. Fierke, A. Ramamoorthy, J. Mol. Biol. 2018, 430, 4230-4244.

[12] B. R. Sahoo, T. Genjo, T. W. Nakayama, A. K. Stoddard, T. Ando, K. Yasuhara, C. A. Fierke, A. Ramamoorthy, Chem. Sci. 2019, 10, 3976-3986.

[13] R. Limbocker, S. Chia, F. S. Ruggeri, M. Perni, R. Cascella, G. T. Heller, G. Meisl, B. Mannini, J. Habchi, T.
C. T. Michaels, et al., Nat. Commun. 2019, 10, DOI 10.1038/s41467-018-07699-5.

[14] A. Faridi, Y. Sun, Y. Okazaki, G. Peng, J. Gao, A. Kakinen, P. Faridi, M. Zhao, I. Javed, A. W. Purcell, et al., Small 2018, 14, 1-13.

[15] B. R. Sahoo, T. Genjo, M. Bekier, S. J. Cox, A. K. Stoddard, M. Ivanova, K. Yasuhara, C. A. Fierke, Y. Wang, A. Ramamoorthy, Chem. Commun. (Camb). 2018, 54, 12883-12886.

[16] M. Wang, A. Kakinen, E. H. Pilkington, T. P. Davis, P. C. Ke, Biomater. Sci. 2017, 5, 485-493.

[17] M. Wang, Y. Sun, X. Cao, G. Peng, I. Javed, A. Kakinen, T. P. Davis, S. Lin, J. Liu, F. Ding, et al., Nanoscale 2018, 10, 19995-20006.

[18] A. Sukhanova, S. Poly, S. Bozrova, É. Lambert, M. Ewald, A. Karaulov, M. Molinari, I. Nabiev, Front. Chem. 2019, 7, DOI 10.3389/fchem.2019.00480.

[19] H. Liu, B. Xie, X. Dong, L. Zhang, Y. Wang, F. Liu, Y. Sun, React. Funct. Polym. 2016, 103, 108-116.

[20] S. Sudhakar, P. Kalipillai, P. B. Santhosh, E. Mani, J. Phys. Chem. C 2017, 121, 6339-6348.

[21] M. F. M. Sciacca, D. Milardi, G. M. L. Messina, G. Marletta, J. R. Brender, A. Ramamoorthy, C. La Rosa, Biophys. J. 2013, 104, 173-184.

[22] M. F. M. Sciacca, F. Lolicato, G. Di Mauro, D. Milardi, L. D'Urso, C. Satriano, A. Ramamoorthy, C. La Rosa, Biophys. J. 2016, 111, 140-151.

[23] T. Ravula, S. K. Ramadugu, G. Di Mauro, A. Ramamoorthy, B. Program, A. Arbor, n.d., 1-11.

[24] T. Ravula, N. Z. Hardin, S. K. Ramadugu, S. J. Cox, A. Ramamoorthy, Angew. Chemie - Int. Ed. 2018, 57, 13421345.

[25] Y. Porat, A. Abramowitz, E. Gazit, Chem. Biol. Drug Des. 2006, 67, 27-37.

[26] K. Yasuhara, J. Arakida, T. Ravula, S. K. Ramadugu, B. Sahoo, J. I. Kikuchi, A. Ramamoorthy, J. Am. Chem. Soc. 2017, 139, 18657-18663.

[27] A. Micsonai, F. Wien, L. Kernya, Y.-H. Lee, Y. Goto, M. Réfrégiers, J. Kardos, Proc. Natl. Acad. Sci. 2015, 112, E3095-E3103.

[28] M. Hagihara, A. Takei, T. Ishii, F. Hayashi, K. Kubota, K. Wakamatsu, N. Nameki, FEBS Open Bio 2012, 2, 20-25.

[29] R. P. R. Nanga, J. R. Brender, J. Xu, G. Veglia, A. Ramamoorthy, Biochemistry 2008, 47, 12689-12697.

[30] Y. Bram, A. Frydman-Marom, I. Yanai, S. Gilead, R. Shaltiel-Karyo, N. Amdursky, E. Gazit, Sci. Rep. 2014, 4, 1-9.

[31] A. Abedini, A. Plesner, P. Cao, Z. Ridgway, J. Zhang, L. H. Tu, C. T. Middleton, B. Chao, D. J. Sartori, F. Meng, et al., Elife 2016, 5, DOI 10.7554/eLife.12977.

[32] D. C. Rodriguez Camargo, K. Tripsianes, T. G. Kapp, J. Mendes, J. Schubert, B. Cordes, B. Reif, Protein Expr. Purif. 2015, 106, 49-56.

[33] S. Bedrood, Y. Li, J. M. Isas, B. G. Hegde, U. Baxa, I. S. Haworth, R. Langen, J. Biol. Chem. 2012, 287, 52355241.

[34] A. Abedini, D. P. Raleigh, Biochemistry 2005, 44, 16284 16291.

[35] K. A. Morrison, A. Akram, A. Mathews, Z. A. Khan, J. H. Patel, C. Zhou, D. J. Hardy, C. Moore-Kelly, R. Patel, V. Odiba, et al., Biochem. J. 2016, 473, 4349-4360.

[36] B. R. Sahoo, T. Genjo, K. C. Moharana, A. Ramamoorthy, J. Phys. Chem. B 2019, 123, 4562-4570.

[37] J. J. Dominguez Pardo, J. M. Dörr, A. Iyer, R. C. Cox, S. Scheidelaar, M. C. Koorengevel, V. Subramaniam, J. A. Killian, Eur. Biophys. J. 2017, 46, 91-101.

[38] M. Xue, L. Cheng, I. Faustino, W. Guo, S. J. Marrink, Biophys. J. 2018, 0, 1-9.

[39] M. Orwick Rydmark, M. K. Christensen, E. S. Köksal, I. Kantarci, K. Kustanovich, V. Yantchev, A. Jesorka, I. Gözen, Soft Matter 2019, 15, 7934-7944. 


\section{Graphical abstract}
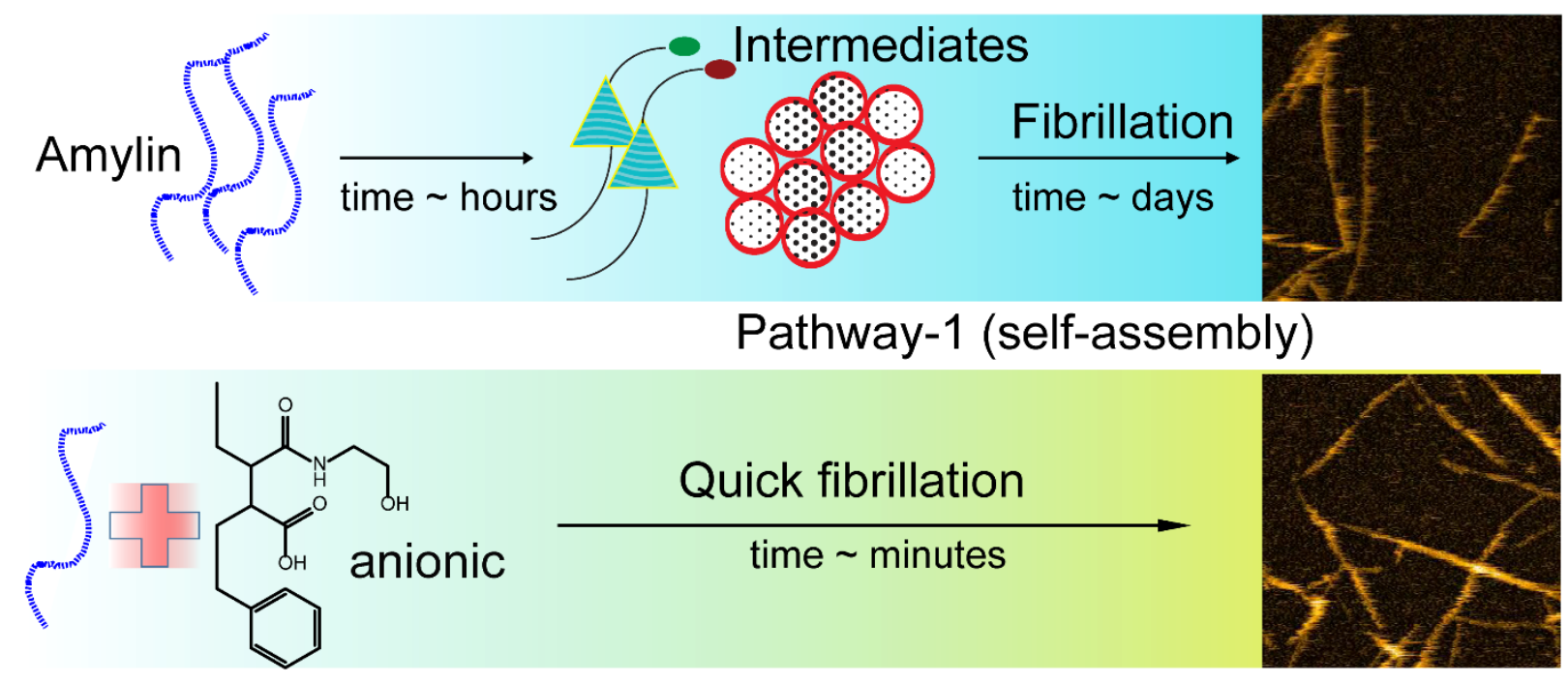

SMA-EA

Pathway-2 (in the presence of anionic SMA)

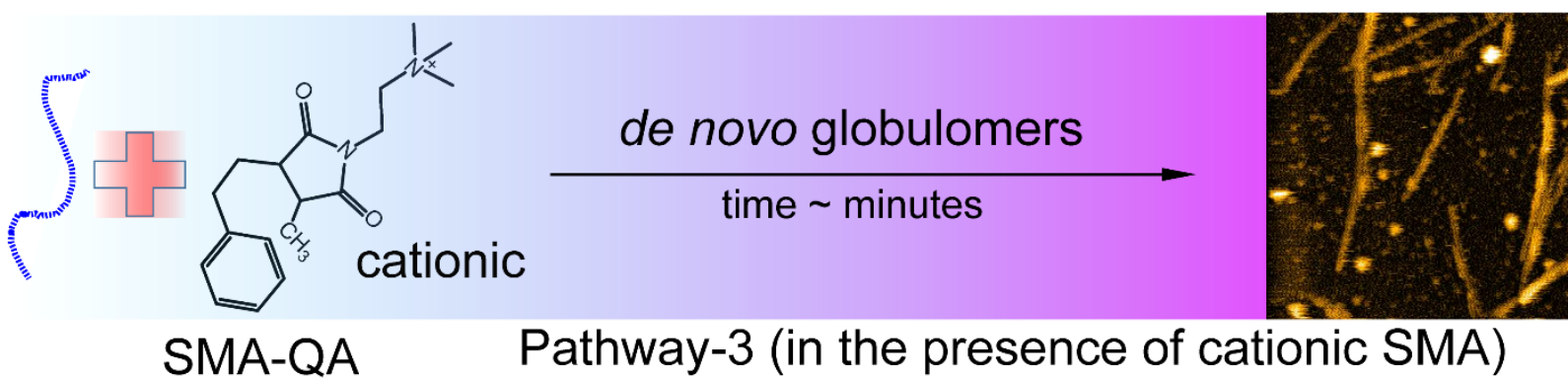

